\title{
IMAGINARIOS SOCIALES DEL DESARROLLO HUMANO, SUBYACEN- TES EN LAS POLÍTICAS DE RESOCIALIZACIÓN DE MUJERES PROFESIONALES INTERNAS, EN EL CENTRO PENITENCIARIO VILLA CRISTINA, DE LA CIUDAD DE ARMENIA, QUINDÍO, COLOMBIA.
}

\author{
SOCIAL IMAGINARIES OF HUMAN DEVELOPMENT, UNDERLYNG IN THE PRO- \\ FESSIONAL FEMALE INMATES RESOCIALIZATION POLICIES OF VILLA CRISTINA \\ PENITENCIARY CENTER IN THE CITY OF ARMENIA, QUINDIO, COLOMBIA.
}

Jesús Amador Quiceno García ${ }^{1}$. Luz Elena Morales Rodríguez¹ . Leda Soraya Cuellar Villa ${ }^{1}$

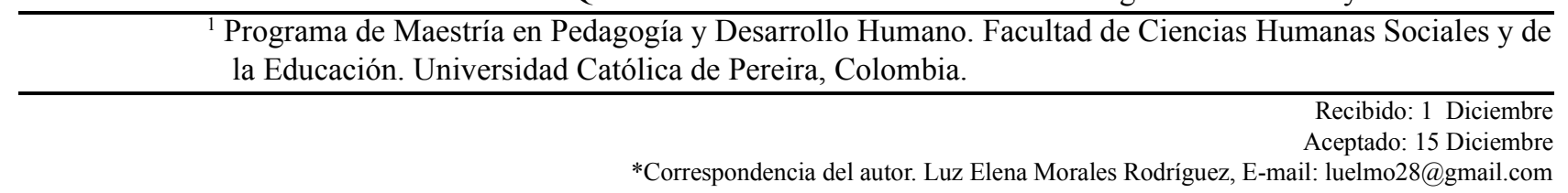

\begin{abstract}
RESUMEN
El presente documento desarrolla una reflexión acerca de los imaginarios sociales inmersos en la política pública de resocialización de las personas recluidas en los centros penitenciarios. Esta política cuenta con unas bases históricas, sociales y culturales, que le permiten al estado postular una propuesta encaminada al desarrollo humano, la cual se encuentra consignada en la ley colombiana. Por tanto, se consideró necesario desarrollar una indagación en torno al concepto del imaginario de la sociedad, respecto a la resocialización en las cárceles, desde la perspectiva del desarrollo humano, tal como lo viven, de modo particular, las profesionales que se encuentran internas en la cárcel de mujeres Villa Cristina, de la ciudad de Armenia, Quindío. Como marco teórico se recurrió al planteamiento de imaginario social de Castoriades, al postulado de desarrollo para la satisfacción de las necesidades humanas de Max-Neef y al razonamiento sobre el aparato disciplinario de Foucault.
\end{abstract}

Palabras claves: Desarrollo Humano, resocialización, sistema penitenciario, imaginarios sociales, imaginario instituido, imaginario instituyente.

\begin{abstract}
This paper is a reflection on the social imaginaries immersed in the public policy for the resocialization of inmates in prisons. This policy has historical, social and cultural foundations, which allow the state to put forward a proposal for human development, which is part of Colombian law. Therefore, we considered it necessary to develop an inquiry regarding the concept of social imaginary concerning resocialization in prisons from the perspective of human development, such as it is experienced, particularly by the professionals who are inmates at the Villa Cristina women's prison, in the city of Armenia, Quindío. As part of the theoretical framework, we resorted to Castoriades' approach to the social imaginary, to the postulate of development for the satisfaction of human needs from Max-Neef, and to Foucault's reasoning on his disciplinary apparatus.
\end{abstract}

Keywords: human development, resocialization, prison system, social imaginary, instituted imaginary, instituting imaginary. 


\section{INTRODUCCIÓN}

Las políticas públicas cuentan con unas bases históricas, sociales y culturales que le han permitido al estado desarrollar sus proyectos gubernamentales encaminados al desarrollo humano del país; por tal razón se hace inminente estudiar el concepto del imaginario de la sociedad, desde las significaciones del lenguaje $\mathrm{y}$ las acciones de los individuos. Es decir, el concepto de imaginario social constituye una categoría fundamental para la interpretación de la comunicación en la sociedad moderna, portadora de las creencias e imágenes colectivas; así pues, lo deseable, lo imaginable y lo pensable de la sociedad actual encuentra su definición en la comunicación pública (Cabrera, 2006).

Dentro de ese imaginario social se ubican las nociones de tratamiento penitenciario, y desarrollo humano, incorporadas en la práctica del proceso de resocialización carcelaria en Colombia. Ello incluye el análisis del impacto producido en un ser humano que es sometido a un proceso intra-mural carcelario, indicando sus formas de ser y estar en el mundo, de dar sentido a su vida y a la de los demás. Lo anterior conlleva también a interpretar, explorar y observar aquellos factores de influencia o aspectos circundantes que entran en juego en la actividad humana, como la cultura, la sociedad, la educación, la política, la familia y el cúmulo histórico; circunstancias que penetran la personalidad y formas de ser del individuo sometido a prisión.

De esta forma, la problemática de la resocialización en Colombia, se puede analizar desde los aportes teóricos sobre desarrollo humano realizados por los pensadores Manfred Max Neef, Cornelius Castoriadis y Michel Foucault. Así mismo, participan de esta reflexión las concepciones del PNUD - Programa de las Naciones Unidas para el Desarrollo, el Código Penitenciario y Carcelario y el Sistema PASO -Plan de Acción y Sistema de Oportunidades-, aplicado en Colombia desde el 2004; fuentes indispensables para entender cómo se presenta la resocialización y la aplicabilidad de las políticas públicas en la praxis de la vida carcelaria.

La idea de Max Neef (1993) de que "solo un estilo de desarrollo orientado a la satisfacción de las necesidades humanas puede asumir el postergado desafío de hacer crecer a toda la persona y a todas las personas", puede ser el marco para interpretar el ámbito de la resocialización. En este escenario, Foucault (2003) advierte que el castigo físico fue abandonado y la condena social comenzó a regirse por el encierro del cuerpo, por tanto, el condenado es encerrado, vigilado y controlado en un sistema que termina abarcando a otras instituciones sociales. En el mismo sentido, Castoriadis (1975), desde la noción de imaginario social, sustenta que la institución carcelaria es un hito del pensamiento colectivo entendido como representación.

En Colombia, a partir de la ley 65 de 1995, en su artículo 10, la resocialización de un infractor debe darse a partir de la disciplina, el trabajo, el estudio, la formación espiritual, la cultura, el deporte y la recreación, bajo un espíritu humano y solidario. Esta realidad carcelaria sintoniza con el autor Manfred Max Neef (1993) y su texto Desarrollo a Escala Humana, donde señala que "una opción por el desarrollo a escala humana requiere estimular el protagonismo de los sujetos para que hagan de la auto dependencia su propia opción de desenvolvimiento".

Este vínculo entre resocialización y desarrollo a escala humana, se encuentra también asociado a lo planteado por el Programa de las Naciones Unidas para el Desarrollo - PNUD (1990) en el Informe sobre Desarrollo Humano donde se afirma que el desarrollo de las personas, en el marco de las opciones y las libertades, "es un proceso en el cual se amplían las oportunidades del ser humano. Significa crear un entorno en el que las personas puedan hacer plenamente realidad sus posibilidades y vivir en forma productiva y creadora de acuerdo con sus intereses".

Actualmente, la realidad vivida en los centros carcelarios colombianos, indica que es urgente tener, no solamente, un conocimiento profundo de la ley, sino que es prioritario interiorizar los lineamientos internacionales que orientan el proceso de la resocialización. En este entorno la propuesta del Estado y sus políticas públicas, antes de los años 90 , tenía como propósito central ayudar a transformar al sujeto retenido, con la opción de brindar educación, ya que un número importante de quienes se recluían eran analfabetas. Sin embargo, hacia la década del 2000 las perspectivas son distintas, ya que a las cárceles empezaron a llegar personas con un alto grado de formación académica; situación que replanteó las urgencias preestablecidas y que viene generando un problema de gobernabilidad al interior de los centros carcelarios. Tal como lo refiere Max Neef (1993), "en la política, la crisis se ve 
agudizada por la ineficacia de las instituciones políticas y representativas, frente a la acción de las élites de poder financiero, por la internacionalización creciente de las decisiones políticas y por la falta de control que la ciudadanía tiene sobre las burocracias públicas". En estas circunstancias, esta investigación ofrece una nueva perspectiva sobre el sistema carcelario del país, a partir de la visión de unas profesionales reclusas que han perdido no sólo la libertad, sino el derecho a satisfacer sus necesidades fundamentales. Estas mujeres cumplen su condena en la cárcel de mujeres Villa Cristina, ubicada en Armenia, Quindío. Sin embargo, durante el momento de este proceso investigativo, año de 2013, se evidencia, no sólo el cambio del paradigma del interno, sino la modificación del imaginario relativo a la resocialización. Es decir, al igual que muchas otras retenidas, las internas de Villa Cristina se encuentran perjudicadas por el mal manejo, no solo de la política pública en torno a la resocialización, sino por la falta de acciones reorientadoras que cumplan con los lineamientos internacionales.

Lo anterior se evidencia incluso con el desconocimiento del objetivo de la política pública de resocialización, por parte de los guardianes del centro carcelario. Esta situación es compartida por las 8978 mujeres reclusas existentes en Colombia, según información del Instituto Nacional Penitenciario y Carcelario (INPEC), a mayo del 2013. Este personal femenino representa el $7.6 \%$ del total de detenidos en el país; de las cuales 257 son mujeres con formación profesional; en donde se incluyen las 28 profesionales reclusas de la región del Viejo Caldas, en donde se ubica la cárcel Villa Cristina.

Es claro que la legislación carcelaria contempla disposiciones para ofrecer un acompañamiento al interno durante su tiempo de condena. El propósito es generar la reflexión, bajo la cooperación y el apoyo del personal administrativo, lo cual debería conducir a alternativas de cambio, de crecimiento personal, y por último hacia la construcción de un nuevo proyecto de vida; potenciando, desde luego, las habilidades y destrezas desde el desarrollo humano. No obstante, se presenta un factor de intervención contrario a lo propuesto, ya que se fomenta al interior de las penitenciarías un fenómeno de sinergia de conductas y condiciones de vida más deprimentes, contradictorias y peligrosas para el interno.

En este sentido, Castoriadis (1980), comenta que "El término Desarrollo comenzó a ser utilizado cuando resultó evidente que el Progreso, la Expansión, el Crecimiento no constituían virtualidades intrínsecas, inherentes a toda sociedad humana, cuya realización (actualización) se habría podido considerar como inevitable, sino propiedades específicas y poseedoras de un valor positivo de las sociedades occidentales". Por tanto, lo más importante para que surja el progreso, o el desarrollo, es la evolución del ser; pues bien, la historia ha indicado que el avance de las sociedades no está sólo ligado al desarrollo económico y al derroche de los recursos naturales, sino al entendimiento del ser. En este sentido, para pensar al ser humano y su relación con el desarrollo se hace necesario estudiar sus imaginarios; así como los imaginarios respecto a las instituciones sociales.

En el ámbito de las cárceles, surge también la categoría "disciplina", que Foucault (2002) define como "técnicas para garantizar el ordenamiento de las multiplicidades humanas". La disciplina en las instituciones carcelarias se ejercita desde lo coercitivo y la imposición, donde se evidencia como ejercicio dominante la comunicación en una sola vía; la cual se convierte en un martirio emocional e inclusive de maltrato hacia la población interna carcelaria. Sumado a esto, el tiempo de estadía intramural, denominada por Foucault "continuidad carcelaria", es la esfera donde más se enmascara el dominio y las incongruencias en la convivencia, por lo que "la difusión de la formaprisión permiten legalizar, o en todo caso legitimar, el poder disciplinario que, de esta manera, elude lo que puede comportar de exceso o de abuso". (Foucault, 2002).

Por consiguiente, el objetivo de la investigación consistió en develar los imaginarios sociales de desarro1lo humano que subyacen en las políticas de resocialización de mujeres profesionales internas en el centro penitenciario Villa Cristina, de Armenia, Quindío. Lo cual conduce también a evidenciar las manifestaciones del contenido instituyente implícito en los discursos de resocialización de las internas; así como identificar las concepciones de desarrollo humano asociados a los imaginarios instituidos, incorporados en la norma y en su implementación en los procesos de resocialización carcelaria y penitenciaria.

\section{METODOLOGÍA}

La presente investigación se desarrolló bajo el enfoque cualitativo, con el método fenomenológico como 
parámetro de acción, el cual, en términos de Denzin y Lincoln (1994) "busca conocer los significados que los individuos dan a su experiencia, en donde lo importante es aprender el proceso de interpretación por el que la gente define su mundo y actúa en consecuencia”. Es decir, allí se enfatiza lo individual y la experiencia subjetiva.

Así mismo, Taylor y Bogdan (1986) consideran, en un sentido amplio, que la investigación cualitativa es "aquella que produce como datos descriptivos: las propias palabras de las personas, habladas o escritas, y la conducta observable". Por tanto, se trata de comprender a las personas dentro del marco de referencia de ellas mismas; en tal sentido, hay un sometimiento a la perspectiva naturalista y a la comprensión interpretativa de la experiencia humana y su análisis.

Con esta metodología de respaldo, la investigación se orientó a conocer el contexto histórico de las internas en su proceso de resocialización carcelaria, el conjunto de sus imaginarios sociales y personales, los desempeños intramurales y las interacciones que se establecen entre ellos; condujo esto también al reconocimiento de emociones, sensaciones, sentimientos, vivencias, pensamientos y creencias expresadas por las reclusas.

La unidad de análisis estuvo representada por todo el contexto de resocialización carcelaria, efectuado para mujeres profesionales internas en la cárcel Villa Cristina de la ciudad de Armenia, en torno al cual se analizaron las nociones imaginarias instituidas e instituyentes de los procesos implantados por la norma PASO y el sistema progresivo penitenciario, como desarrollo humano, resocialización, reivindicación, reinserción, entre otras.

Como instrumento investigativo se utilizó la entrevista directa con reclusas en el medio carcelario y con profesionales que apoyan, desde su rol administrativo y profesional, algunos de los procesos carcelarios. Dichas entrevistas también se abordaron en el contexto de un grupo focal, para lo cual se establecieron unas preguntas orientadoras predefinidas, pero conservando una entrevista flexible y dinámica; es decir, no estandarizada o estructurada, de tal forma que los participantes expresaran tranquilamente sus opiniones y significados. En términos de Escobar y BonillaJiménez (2011) "los grupos focales son una técnica de recolección de datos, mediante una entrevista gru- pal semi estructurada, la cual gira alrededor de una temática propuesta por el investigador"; es decir, su propósito principal es hacer que surjan actitudes, sentimientos, creencias, experiencias y reacciones en los participantes, que desde luego, comparten una experiencia en común.

Así mismo, la información obtenida fue analizada e interpretada de tal forma que permitiera explorar el significado de las experiencias narradas y documentadas, para lo cual se procesó una matriz de datos codificados. La organización de los datos en la matriz se realizó desde la triangulación investigador, teoría y participantes; analizando la narrativa de cada participante, sus significados, explicaciones, sentidos y percepciones, acerca de la interpretación del Código Penitenciario y Carcelario Colombiano y el verdadero sentido del proceso resocializador en mujeres profesionales, como población de ingreso actual .

\section{RESULTADOS Y DISCUSIÓN}

Bajo la óptica de esta investigación es evidente que para el INPEC (2013), la mirada ya no está puesta en la persona, sino en la pena y en el simple hecho de "cuidar a unas delincuentes", en palabras de un integrante del grupo focal. Dicho organismo no tiene normas para los reclusos sobre educados, es decir, que ya superaron la meta de graduación bachiller que dispone el penal; por ello se encuentran casos como el de un médico, quien se gradúa en panadería, por cuanto no existe acceso a otro nivel educativo superior. De allí que los profesionales encarcelados se conviertan, en muchas ocasiones, en una dificultad para el penal, aparte de que también son maltratados sicológicamente, por cuanto se les recalca permanente su condición de internas.

No obstante, en Colombia las profesionales internas han ido ganando espacios, como lo afirmó la funcionaria del ministerio de Defensa Nacional en el grupo focal, refiriéndose al caso de otras cárceles del país. Esta situación se ha venido replicando en la cárcel de mujeres de Armenia, en donde las reclusas profesionales ahora son monitoras y una de ellas, es representante de los Derechos Humanos, con una votación de las internas inimaginable para las guardianas. Esta delegada expresó en una de sus intervenciones: "pero no olviden que si reclamamos los derechos también deberemos vivir los deberes", lo cual indica el nuevo giro respecto al papel que pueden desempeñar este tipo de reclusas. 
En cuanto a la política pública, se comprobó en las entrevistas a los diferentes dirigentes y guardianes encargados de las internas, que muchos de ellos no conocen suficientemente la normatividad carcelaria. Se constató también que no existe un real interés en estos seres humanos allí recluidos, puesto que para ellos son solo delincuentes, aun sabiendo que sus "delitos" no revisten impactos mayores, como los de lesa humanidad.

En este sentido, surgen unas categorías emergentes y transversales referidas por los mismos funcionarios administrativos y las internas, las cuales se reflejan en afirmaciones como: "falta engranaje de la familia, ya que el contacto con ella se queda solo en la entrada a la cárcel... a partir de incluso unas requisas inhumanas para las familias en donde se evidencia esa falta de lo humano en los que dirigen". Estas apreciaciones se relacionan con posibles maltratos a padres, esposos e hijos de las internas, en el momento de las visitas mensuales, en donde no se propician espacios y tiempos de calidad para el encuentro con los seres queridos. Así mismo el entorno social, se convierte en amenazante para ellas, cuando sus condenas son divulgadas en los medios de comunicación y se las sindica como "lo peor de la sociedad".

En estas dinámicas es cuando la misma ley de resocialización se vuelve contradictoria, lo que se confirma en el hecho de que las familias no son vinculadas estructuralmente al propósito de la reincorporación del recluso a la sociedad. Durante las visitas, por ejemplo, las requisas, a veces traumáticas, se realizan a discreción de las cabos y comandantes de turno, en donde se evidencia lo subjetivo y arbitrario de las decisiones de algunos guardianes, con restricciones injustificadas y grosería en el trato. Además, se presenta el fomento de la mendicidad y la pérdida de lo humano, incluidos los ideales de bienestar, en los eventos en donde algunas internas viven mejor calidad de vida adentro de la cárcel que afuera, por lo que la reincidencia se vuelve una opción de vida.

El sistema carcelario de Colombia padece un momento histórico de hacinamiento. Según el informe del INPEC (2013), en 138 establecimientos de reclusión, con una capacidad real de 75.726 cupos, se alberga una población de 117.528 presos; desde luego esta situación crítica hace cada vez más difícil una verdadera practica resocializadora, en donde se vea al hombre completo o íntegro. Así pues, se ve truncada la aplica- bilidad de los buenos propósitos de las normas, ya que el sistema está centrado en esa gran masa por vigilar y no por resocializar. Ello se evidencia en las profesionales recluidas, objeto de esta investigación, quienes por la inconsistencia de la ley, no pueden ejercer de acuerdo con sus profesiones.

Lo anterior muestra como las profesionales entrevistadas van quedando reducidas a la angustia del encierro y a la pérdida de su esencia como ser social, por un lado, por la falta de lucidez administrativa y estatal, al no tener alternativas para lograr los procesos de resocialización ya contemplados en la ley; y además, por la insensibilidad de las guardianas hacía las personas que están bajo su tutela.

\section{La resocialización bajo los lineamientos de la ley}

La ley 65 de 1995, por medio de la cual se expide el Código Penitenciario y Carcelario Colombiano establece en sus artículos 9 y 10 que "la pena tiene función protectora y preventiva, pero su fin fundamental es la resocialización. Las medidas de seguridad persiguen fines de curación, tutela y rehabilitación". Así mismo "El tratamiento penitenciario tiene la finalidad de alcanzar la resocialización del infractor de la ley penal, mediante el examen de su personalidad y a través de la disciplina, el trabajo, el estudio, la formación espiritual, la cultura, el deporte y la recreación, bajo un espíritu humano y solidario".

De igual manera, en los artículos 142 y 143, se establece que el tratamiento penitenciario se basará en "las características particulares de cada sujeto y en el estudio científico de la personalidad del mismo, como forma de integración positiva a la sociedad". No obstante, a partir de las entrevistas realizadas en la cárcel Villa Cristina de Armenia, se confirmó que allí no existe tratamiento diferenciado, solamente se menciona un programa de comunidades terapéuticas para toxicómanos, el cual se aproxima a este ideal. Por lo demás, el tratamiento penitenciario es igual para todas las internas, en contradicción con lo planteado en la norma jurídica.

En la legislación Colombiana el INPEC es el directo responsable de administrar el Sistema Penitenciario y Carcelario, así como del diseño y ejecución de los diferentes programas de resocialización. Dichos procesos están enfocados a personas procesadas que en su gran mayoría son provenientes de sectores vulnerables, quienes cometen delitos con finalidades econó- 
micas. Según el INPEC (2013) "la educación formal agrupa programas de alfabetización, educación básica primaria, secundaria y superior. La no formal se brinda con el objeto de complementar, actualizar, suplir conocimientos y formar en aspectos laborales o académicos. Finalmente la informal corresponde a todo conocimiento libre y espontáneamente adquirido".

Los principios de la administración carcelaria son abordados a partir del sistema P.A.S.O. -Plan de Acción y Sistema de Oportunidades-, aplicado en Colombia desde el 2004. Este plan es una propuesta de atención y tratamiento diseñado para la población reclusa, basado en el sistema progresivo y buscando con ello la humanización del tratamiento, mediante procesos de resocialización, cambiando así algunos hábitos durante cumplimiento de la pena. La idea es que el interno elabore, desde que ingresa a la penitenciaria, una ruta de acción para su tratamiento y preparación para la vida. (UNAL \& INPEC, 2008). De igual forma, el sistema progresivo pretende la disminución de la pena impuesta, teniendo en cuenta factores objetivos y subjetivos, es decir que el interno se piense y actúe como un ser autónomo y que dependiendo de su comportamiento, actitud y progreso en la asimilación de la pena y el tratamiento, pueda llegar a disponer de libertad anticipada, cumpliendo con estudio, trabajo o enseñanza.

El significado del sistema PASO es una rehabilitación, donde el sujeto encuentra un sentido para su vida, asociado hondamente a lo laboral; el trabajo es visto como preponderante para dejar de ser infractor y como medio para redimir la pena. El objetivo principal es evitar el aislamiento del sujeto y propiciar espacios de reflexión y evaluación personal para lograr una persona capaz de adaptarse al ambiente, durante su proceso de crecimiento. El tratamiento penitenciario hoy piensa al delincuente como un sujeto cuya identidad es indeseable o insatisfactoria, entendiendo que el componente esencial de la ejecución de la pena es la resocialización.

Al retomar los principios de la administración carcelaria, y en especial las que respaldan la resocialización, es necesario precisar que esta se aborda en la ley desde la perspectiva de la humanización a la atención de la población de internos, con una adecuada asistencia a su tratamiento, un bienestar intramural integral y planes para la reinserción social. Dicha humanización no debe estar referida exclusivamente a solucionar el problema del hacinamiento, con el que se cuenta en la actualidad y el cual se considera como el más importante dentro de lo contemplado como derechos humanos.

El informe estadístico del INPEC, de Mayo de 2013, confirma que "la limitación y carencia infraestructura adecuada, impide que el Instituto brinde las garantías mínimas de servicio en las áreas laboral, de salud, recreación, bienestar, educación y en general, todas las acciones encaminadas a preparar al condenado mediante su resocialización para la vida en libertad"; lo que indica que las dificultades actuales para el contexto carcelario, son de alto nivel y que ameritan de manera urgente de reflexión, seguimiento y cambio de estrategias a otras más funcionales y cercanas a la realidad social.

\section{La resocialización desde Max-Neef}

De otro lado y respecto al valor de lo humano, los administrativos del INPEC afirman que "hay que tener el interno ocupado que no tenga tiempo de pensar nada y se canalice lo emocional". Ello representa una premisa de control y resocialización a partir de la disciplina, aunque en categorías de Max Neef (1993) una necesidad no satisfecha es el nacimiento de nuevas necesidades. Esto se corrobora, con la pérdida de ciertos satisfactores: "En el patio no se descansa", afirman las internas; "por el contrario todas alli se cansan y se estresan más por las peleas y demás cosas que se desencadenan allí, más cuando el número elevado de internas hace más diversos los estados de ánimo allí propuestos". En el mismo sentido se expresa: "no existen principios ni moral, solo alcahuetería, la guardia no da de lo que no tiene"; esto lo afirman acerca de guardianes que favorecen solo a algunas internas de su agrado y no haciendo válido el derecho de todas a los mismo privilegios.

En términos del Max-Neef, en ocasiones los satisfactores a veces se vuelven destructores; es decir, las necesidades humanas, no solamente se satisfacen con bienes y servicios, sino con prácticas sociales y formas de organización que repercuten en el bienestar del ser humano. En este esquema, el ser y el estar son necesidades que requieren satisfactores de reconocimiento, de pertenencia y de protección, es por ello que las reclusas, a pesar de estar apartadas de la sociedad, pueden ser útiles al grupo social en el que están inmersas. 
En el entorno de la resocialización carcelaria, "facilitar una práctica democrática más directa y participativa puede contribuir a revertir el rol tradicionalmente semi-paternalista del estado, en rol estimulador de soluciones creativas que emanen desde abajo hacia arriba y resulten por lo tanto, mas congruentes con las aspiraciones reales de las personas". (Max-Neef, 1993). Este planteamiento es atribuible a las internas, quienes en el mundo carcelario deben ser objeto de satisfactores sinérgicos y no de satisfactores violadores o destructores. De ahí que el problema carcelario va más allá de la simple mirada resocializadora, educadora y deportiva, se debe mirar un "desarrollo a escala humana, orientado en gran medida hacia la satisfacción de las necesidades humanas, lo que exige un nuevo modo de interpretar la realidad" (Max-Neef, 1993), ya que el ser humano recluido, no solo pierde su utopía, sino muchos derechos mínimos, como la posibilidad de contemplar la naturaleza. En la cárcel Villa Cristina, como se comentó en el grupo focal, "algunas reclusas no toman el sol, porque para esto deben pagar a otras internas (por la ubicación en el patio), no ven la luna porque son encerradas temprano y no duermen bien".

Pensar sólo en el delito y no en la persona, contrario a lo que tienen escrito en las frases de entrada a las cárceles, ha desviado la mirada por el sujeto; lo que se refuerza con el hecho de que las cárceles clasifican a los internos por el tipo de delitos y no por los procesos resocializadores, pensados desde lo humano. En términos de Max-Neef (1993) "esta otra racionalidad se orienta por el mejoramiento de la calidad de vida de la población, y se sustenta en el respeto a la diversidad y en la renuncia a convertir a las personas en instrumentos de otras personas". Así pues, urge una política pública que se piensa desde la base, desde el patio, "desde la mirada de la interna", como lo afirmaban algunas reclusas en las entrevistas.

En lo que toca a los satisfactores del conocimiento en la teoría de Max Neef, ellos se relacionan con la estructura, la alimentación, el abrigo, la educación formal e informal, el estudio, la investigación y la meditación; y entre los satisfactores de la protección encontramos la salud, la curación y la prevención. Ahora bien, el satisfactor debe entenderse como el modo por el cual se expresa una necesidad, de allí que ellos ayudan a dar a la organización de las estructuras políticas, valores, normas, espacios, contextos, comportamiento actitudes. Todo lo manifestado como ele- mento de ayuda, se ve enfrentado a unos violadores, destructores y aniquiladores, estos son elementos que paradójicamente aplicados a los contextos de provecho de una necesidad, aniquilan la posibilidad de su satisfacción.

En la confrontación de dos visiones del proceso de resocialización, encontramos el postulado de MaxNeef de impulsar la fuerza participativa, para encontrar el desarrollo a escala humana. En las entrevistas un funcionario administrativo estimó la vida carcelaria como un "proceso de orientación que se realiza a todas las personas privadas de la libertad inculcando varias áreas, valores principios desde el punto de vista moral, cultural, religioso,"; opinión distante de una de las internas quien manifestó que "en el caso de las personas del común las vuelve reincidentes, la ley es muy contradictoria, la condición de vida es en contravía, lo social no es mirado, es ilógico, la cárcel no resocializa, las condiciones mentales no son las mejores". Por tanto, se debe estimular la constitución de sujetos sociales capaces de sostener un desarrollo autónomo, auto sustentado y armónico, todo orientado a mejorar la calidad de vida.

\section{La resocialización desde Castoriades}

Siguiendo el planteamiento de Cornelius Catoriades, la sociedad bien puede compararse a un ser vivo, por cuanto se desarrolla, se organiza a sí misma y tiene la capacidad de transformarse; estos cambios a su vez pueden verse a través del lenguaje, es por ello que hay un lenguaje para el tiempo de la guerra y otro para el tiempo de la paz. En tal circunstancia, las significaciones son las que cambian, y para que se dé el cambio se deben dar transformaciones de las significaciones del lenguaje. Por tanto, cada sociedad va creando su tiempo calendario e histórico y el tiempo imaginario; la sociedad hace su tiempo imaginario, el cual tiene que ver con el hacer de una sociedad, lo que se vive, lo que se inventa y lo que se sueña, por lo que el lenguaje de las significaciones, encarna los imaginarios sociales.

Para entender la institución imaginaria de la sociedad Castoriades señala que "utilizamos estos términos de la misma manera en que un caballo utiliza los desniveles del suelo en su galope. Que haya suelo y huellas es la condición y la consecuencia de la carrera; pero lo que queremos aprehender es la carrera". Desde esta perspectiva se puede argumentar entonces que la realidad es en este caso, la de una multitud de institucio- 
nes seguidas de individuos socialmente categorizados (como capitalistas y como proletarios), creaciones histórico-sociales que se mantienen unidas gracias a la referencia común, gracias a las cuales aquellas creaciones sociales son en general y para cada individuo (Castoriades, 1983).

La sociedad da existencia a un mundo de significaciones y ella existe en referencia a ese mundo. Precisamente lo que mantiene unida a una sociedad es el mantenimiento conjunto de su mundo de significaciones y lo que permite pensarla es la particularidad o especificidad de su mundo de significaciones. Por ejemplo, la institución carcelaria y todo el sistema, son significaciones imaginarias sociales, a partir de las cuales una multitud de situaciones son socialmente representadas y reflejadas. Esta significación es convertida en una multitud de significaciones referidas a objetos concretos, como el sujeto criminal, la cárcel, la ley y la resocialización, el sistema penal acusatorio, entre otros. También existen unas significaciones abstractas, como los prejuicios sociales, la pérdida de los derechos humanos y casi la imposibilidad de resocialización, por cuanto no se cumple con los beneficios primarios o fundamentales que debe tener el interno como ser humano que sigue siendo instituido.

Entonces, lo instituyente sería, que se presente una transformación social de los valores existentes, de tal manera que la resocialización en la institución carcelaria sea una actividad social efectiva, que sea real y que se lleven a cabo procesos en los que el desarrollo humano sea lo primario. Bajo estos parámetros dicha resocialización no estaría mediada por situaciones tales como el hacinamiento y la pérdida de los derechos humanos, el cual hace que las personas encargadas de los procesos de vigilancia carcelaria prefieran brindar la prisión domiciliaria a muchos internos, por cuanto el mismo estado no tiene como controlar los altos índices de criminalidad que existe. Examinar los imaginarios requiere descubrir a través del hacer y el decir de los individuos las representaciones sociales que sobre el desarrollo humano se han construido, en este caso, en la cárcel Villa Cristina. Así pues, es importante reconocer que la cárcel se debe entender como una institución que hace parte de la sociedad, soportada en un mundo de significaciones imaginarias que ella crea y recrea permanentemente.

En las diferentes entrevistas se encuentra que el imaginario que se tiene sobre la resocialización está muy cerca a considerarla como un verdadero fracaso; así lo argumenta uno de los jueces entrevistados, al decir: “¿Qué tanto de manera alguna sirve la prisión para trasformar a un delincuente en un ciudadano respetuoso de la Ley y de las costumbres sociales del territorio donde se asiente?, máxime cuando la mayoría de internas en la Cárcel están alejadas de su familia, purgando penas altas, solamente en aras de que mientras se ejecuta la sentencia, la sociedad se vea protegida de este tipo de damas que por su actividad delictiva, han resultado condenadas.". Aquí se refleja una gran decepción ante la falta real de un proceso de resocialización, considerando entonces que la finalidad de la reclusión en un centro intramural es únicamente el aislamiento de la condenada.

Al respecto también argumentó uno de los defensores públicos penalista así: "las mujeres que han permanecido privadas de la libertad cumpliendo una pena, en cárceles totalmente hacinadas, donde lo que han mostrado es un deterioro en sus condiciones generales: problemas de salud, desarraigo, rompimiento de vínculos familiares, amistosos y laborales... En esas condiciones, no es posible hablar de desarrollo humano en el proceso de resocialización, sino de un verdadero retroceso en sus condiciones, dado que muchas veces, delincuentes primarias se vuelven avezadas perpetradora, quienes además crean resentimiento hacia la sociedad y hacia el Estado".

Lo antes dicho permite ver que el imaginario instituido respecto a la resocialización es deficiente, porque verdaderamente no tiene en cuenta a la persona y su potencial de desarrollo, mucho más si se trata de internas que han ingresado como profesionales. También se percibe que la falta de planes que conlleven a lograr el desarrollo humano, hace que se presente en las internas la pérdida de la finalidad del cumplimiento de la pena y a su vez la significación social de la institución carcelaria.

En este contexto, la problemática actual del hacinamiento en las cárceles conlleva a la vulneración de derechos humanos, como el derecho a la vida digna y a la salubridad. En el caso de Villa Cristina, dicha situación no les permite a las recluidas desarrollar al máximo su ser; con un agravante, una interna que ingresa a la cárcel a pagar una condena por un delito menor, a través del lenguaje y del accionar de las demás internas que se encuentran por delitos más severos, puede quedar inmersa en un factor desencadenante de de- 
rrumbamiento ético, en cuanto a principios y valores, lo que la dejaría frente a la posibilidad de reincidir en la comisión de nuevas conductas punibles. En tal cúmulo de significaciones queda conectada la resocialización, pero también la necesidad de los cambios que se deben realizar en los centros penitenciarios, de tal manera que una persona que se encuentra allí recluida, a pesar de haber delinquido, seguirá siendo un ser humano digno de una oportunidad para convertirse en un ser útil, tanto para la familia como para la comunidad.

De otro lado, la institución carcelaria, incluido todo el sistema, así como la resocialización, tiene unas significaciones imaginarias sociales, referidas a objetos concretos, como el sujeto criminal, la cárcel, la ley y la resocialización, el sistema penal acusatorio, entre otros y unas abstractas, como los prejuicios sociales, que son los que tienen el común de las personas que desde lejos perciben tal situación y que la experiencia los ha llevado a dudar de los resultados del proceso mismo. Más allá se tiene que el imaginario instituyente es lo que está por transformarse, desarrollarse, organizarse; cambio que debe darse a través del lenguaje y de las acciones, dando lugar al cambio de las significaciones. El nuevo imaginario social, respecto del interno de una cárcel, podrá visualizar al ser humano que logró efectivamente mejorar su desarrollo humano, donde sea visto como un ser que transforma su delito en mejoramiento y resarcimiento social.

Junto con el discurso de resocialización, tienen lugar otros discursos anexos de máxima importancia, los cuales están inmersos obligadamente en el diario vivir de las internas en los centros penitenciarios y su cohabitar con el personal administrativo y de la guardia del centro carcelario. Uno de ellos es el de los derechos humanos, categoría que transversaliza todo el ejercicio penitenciario y resocializador y del cual se hace referencia a los derechos individuales como son: la libre expresión, el no sometimiento a tratos crueles, inhumanos o degradantes. Otro discurso se refiere a los derechos sociales, económicos y culturales en especial a: derecho al trabajo en condiciones equitativas y satisfactorias, derecho a la salud física y mental, a la educación en sus diversas modalidades; y para el caso de los derechos colectivos se destaca el derecho a la coexistencia pacífica.

Tales derechos a pesar de estar contemplados en la ley y ser objeto de acatamiento por toda la sociedad, son visiblemente vulnerados en las prácticas resocializadoras intramurales, en eventos como los malos tratos, la discriminación, el coartamiento de la libre expresión, el impedimento para tener contacto con su familia y que esta sea un elemento fundamental para el ejercicio de resocialización.

\section{La resocialización desde Foucault}

La creación de la cárcel surge ante la necesidad de proteger el secreto del procedimiento ante la delincuencia; examinando sus antecedentes y con el trascurrir del tiempo se pasa de las actuaciones o torturas promovidas en público, a una ejecución cada vez más discreta, hasta desaparecerla por completo del panorama público; el tipo de castigo en torturas, consideradas como inhumanas, tenían que ser modificadas o cambiadas por otro sistema más humano.

Plantea Michel Foucault (2002) que el castigo a través de la tortura dio lugar al cambio de apreciación sobre la forma de corregir al delincuente, encontrando como técnica la prisión, como una elección por defecto, pues halló que la privación de la libertad se convertía en la práctica restrictiva más adecuada y menos cruel que la tortura, la que él posteriormente denominó "institución disciplinaria". Por tanto, la cárcel se asocia al lugar de cumplimiento de las penas privativas de la libertad, lo cual indica que es un establecimiento predestinado para la retención y custodia de detenidos y presos, cuyo objetivo primordial es lograr que las personas concentradas en ella rectifiquen su conducta. Desde el inicio se reconoce que las cárceles deben ser modificadoras de actitudes y lo que se espera con el transcurso de la resocialización es que una vez salgan de los centros de reclusión, tengan la posibilidad de conseguir un trabajo que los aleje de la delincuencia.

Lo que se pretende al recluir a un individuo es que esté excluido de la sociedad, para que de ese modo pueda entrar en un proceso de reflexión de sus malos actos y llegue a la conclusión de que tiene que cambiar su manera de ver la vida. A nivel doctrinario se han manejado múltiples significados sobre ese ideal resocializador, comúnmente se utilizan conceptos como resocialización, reinserción, reeducación, readaptación, sin un claro contenido de qué es lo que realmente se pretende, pues este es otro proceso original que pocas veces nos es dado observar en la realidad y contexto.

La dinámica resocializadora inevitablemente se remi- 
te al pasado de la persona y trata de interesarse en el cambio de la información que obtuvo y que la condujo a realizar el acto delictivo, por lo cual esta postura fácilmente imagina de manera prejuiciosa "criminal" a la persona antes de haber cometido el hecho que se juzga como delictivo. Esta noción imaginaria del sujeto genera una valoración subjetiva negativa del individuo y de alguna circunstancia de su formación personal que lo llevó a cometer un delito.

Al buscar que las internas profesionales de las cárceles Villa Cristina de Armenia entiendan e internalicen los conjuntos valorativos dominantes en la sociedad, se espera que no vuelvan a trasgredir la ley, adecuando sus conductas a principios morales congruentes, lo cual deja en evidencia que ésta perspectiva está en contraposición con los derechos humanos como la autonomía individual y la libertad ideológica, y donde, como resultado, se da una desigual intromisión de acciones improcedentes que producen la violación de más derechos que los esperados en brindar a las personas privadas de la libertad.

De acuerdo con lo anterior, las críticas a este proceso resocializador no solo se centran hacia las estrategias, sino a los medios empleados para conseguirlo, pues como condición básica, según Foucault (2002), se genera un "suplicio simbólico" el cual hace parte de manera visible de manifestaciones de poder donde "el cuerpo solo se convierte en fuerza útil cuando es a la vez cuerpo productivo y cuerpo sometido". Es así como los sujetos a resocializar son tratados bajo un imaginario individual creado por cada uno de los encargados de generar y aplicar las estrategias contempladas por el sistema penitenciario y donde se olvida abordar el ser tal como lo refiere Foucault (2002) "el cuerpo, la imaginación, el sufrimiento, el corazón que respetar no son en efecto los del criminal que hay que castigar", esto es, el sujeto que comete un delito debe tener la oportunidad de potenciar sus ideales, cuidar su cuerpo, fortalecer sus valores, pues en el fondo es la "falta" lo que hay que sancionar.

Entonces, se debe abordar el significado de la disciplina como un proceso educativo-formativo, opuesto a la creencia popular de que el significado de la disciplina es casi exclusivamente el de castigar a las personas; como lo afirma Foucault "la prisión debe ser un aparato disciplinario exhaustivo. En varios sentidos debe ocuparse de todos los aspectos del individuo, de su educación física, de su aptitud para el trabajo, de su conducta cotidiana, de su actitud moral, de sus disposiciones....", distinto a aquella afirmación por parte del actor administrativo de la cárcel Villa Cristina, donde refiere que "... hay que tener el interno ocupado que no tenga tiempo de pensar nada y se canalice lo emocional...".

\section{CONCLUSIONES}

Las normas carcelarias colombianas se encuentran bien sustentadas, pero su introducción a la realidad penitenciaria no es óptima; por tanto, las cárceles deben ser replanteadas porque no se obtiene una verdadera resocialización de los reclusos. Por tanto, es urgente una política pública que surja de la base carcelaria del país, la cual incluya aspectos determinantes como un manual de convivencia y una formación orientada hacia el desarrollo humano.

El proceso de resocialización de la cárcel Villa Cristina de Armenia se centra en actividades educativas y laborales del tipo manualidades, desconociéndose las potencialidades y las capacidades de las internas profesionales y excluyéndolas de la oportunidad de aplicar sus conocimientos específicos, dentro del centro penitenciario, como beneficio bilateral para el proceso hacía la reintegración social.

En el proceso de resocialización con el que cuenta la cárcel Villa Cristina de Armenia se debe corregir la vulneración de los Derechos Humanos de los internos, en el marco del Artículo 62 del estatuto penitenciario, en donde se dispone que "Los internos en los centros de reclusión, serán separados por categorías, atendiendo a su sexo, edad, naturaleza del hecho punible, personalidad, antecedentes y condiciones de salud mental y física...". Uno de los aspectos que vulnera los derechos humanos es que a las profesionales condenadas, en la Cárcel Villa Cristina, no se les permite apoyar con su trabajo comunitario, el proceso de resocialización en la institución carcelaria.

Se considera importante plantear un tratamiento de resocialización diferenciado para las distintas poblaciones de internos, ya que la tipología de persona que está ingresando en estos tiempos a los centros de reclusión está cambiando. Sumado a esta dinámica, es necesario fortalecer el sujeto a través del desarrollo humano, que caracterice esta población carcelaria, de manera que sea ajustable a la cotidianidad, que pueda ser flexibilizado de acuerdo al delito infringido y al nivel educativo de las internas . 
El proceso resocializador planteado desde el sistema PASO, en especial el referido a la cárcel de mujeres de Armenia, no se aplica adecuadamente; esto se evidencia incluso en el no conocimiento del objetivo de la política pública por parte de la guardia carcelaria. En este sentido, la familia, como eje fundamental de la sociedad, no ha sido tomada como parte esencial del proceso resocializador, a pesar de estar contemplado en la normatividad.

El hacinamiento actual hace cada vez más difícil una verdadera práctica resocializadora que vea al hombre completo o íntegro, ya que la aplicabilidad de los sanos propósitos de las normas se ve postergada por la necesidad de vigilar a la masa. El rol del Estado en las políticas públicas debe propiciar una mayor participación, de tal forma que el desarrollo a escala humana estimule la constitución de sujetos sociales capaces de sostener un desarrollo autónomo y armónico.

Nace una nueva concepción respecto del ser, saber y el hacer de las mujeres profesionales internas, por tanto su resocialización ha de orientarse primordialmente hacia la adecuada satisfacción de sus necesidades. Lo anterior no logra llevarse a la práctica, ya que no se presenta una adecuada oportunidad, inspirada en la humanización del tratamiento carcelario.

El problema carcelario va más allá de la simple mirada resocializadora, educadora y deportiva, ya que el ser humano allí recluido, como persona, tiene múltiples necesidades que son interdependientes y de esa misma manera debe contemplarse la interdisciplinariedad en la solución del problema, puesto que no solamente debe observarse la aplicación de la ley, sino los factores económicos, sociales, antropológicos, biológicos, psicológicos y ecológicos.

Se necesitan transdisciplinas coherentes y significativas en la aplicabilidad de la norma, incorporando cambio de paradigmas frente al problema de la resocialización, teniendo en cuenta que cualquier necesidad humana fundamental no satisfecha, en este caso, revela pobreza de subsistencia, protección, afecto, autoritarismo y negación de las relaciones con el medio ambiente natural.

Existe una evidente discrepancia entre lo teórico, la normatividad legal, las políticas públicas y el funcionamiento real de las cárceles; agregado esto al fenómeno de la población cambiante en el ámbito carcelario. Por tanto, los programas diseñados deben ser acordes a dicha realidad, superando la primacía del tiempo y generando agilidad en la función resocializadora que involucra el sistema penitenciario y la población carcelaria.

La resocialización es un proceso que se encuentra instituido jurídicamente, pero para el imaginario de la gran mayoría es un fracaso, es una ilusión, no se da el verdadero cambio que se requiere, en quien ha tenido como vivencia la cárcel. Por el contrario, lo que se presenta es un retroceso del desarrollo humano, donde el imaginario social sobre una persona que sale de una cárcel seguirá siendo el del ser una persona no digna de confianza.

A nivel general, la estructura del sistema PASO busca dar cumplimiento a unas expectativas resocializadoras del proceso penitenciario, pero este a su vez se ve limitado en la praxis frente a la nueva población de internas profesionales. Se evidencia entonces divergencia entre lo instituido y la realidad personal y social del ejercicio resocializador; con una evidente limitación y sesgamiento del concepto de persona y del acompañamiento por parte de personas capacitadas e idóneas que faciliten el proceso desde la práctica de los derechos humanos.

Se considera importante plantear un tratamiento de resocialización diferenciado para las distintas poblaciones de internos, ya que la tipología de persona que está ingresando en estos tiempos a los centros de reclusión está cambiando, y sumado a esta dinámica, es necesario fortalecer el sujeto a través del desarrollo humano, que caracterice esta población carcelaria, de manera que sea ajustable a la cotidianidad, que pueda ser flexibilizado de acuerdo al delito infringido y al nivel educativo de la interna, que permita una maximización del recurso humano con el que se cuenta. 


\section{BIBLIOGRAFIA}

- Agudelo, P. A. (2011). (Des)hilvanar el sentido/los juegos de Penélope. Una revisión del concepto imaginario y sus implicaciones sociales. En: Unipluridiversidad, Vol.11 No.3, 2011 -Versión Digital, Facultad de Educación- Universidad de Antioquia. Medellín, Col.

- Cabrera, D. H. (Coord.) (2008). Fragmentos de caos. Filosofia, sujeto y sociedad en Cornelius Castoriadis, Edit. Biblos, Buenos Aires, 2008. 307 páginas, ISBN 978-950-786-648-7 www. editorialbiblos.com.

- Cabrera, D. H. (2006). Imaginario social, comunicación e identidad colectiva. Recuperado en: http://www.portalcomunicacion.com/dialeg/paper/pdf/143_cabrera.pdf

- Castoriadis, C. (2006). Una sociedad a la deriva. Entrevistas y debates (1974-1997). Buenos Aires: Katz.

- Castoriadis, C. (1995). La democracia como procedimiento y como régimen, en: Leviatán. Revista de derechos e ideas. No. 62, Madrid. pp. 65-83.

- Castoriadis, C. (1983). La institución imaginaria de la Sociedad. Buenos Aires: Edit. Tusquets.

- Castoriadis, C. (1980). El mito del desarrollo. Reflexiones sobre el desarrollo y la racionalidad. Buenos Aires. Edit. Kairós. Disponible en: http://books.google.com.co/books?id=DO5J6S5BwE $\mathrm{wC} \&$ printsec $=$ frontcover\&hl $=$ es\&source $=\mathrm{gbs}$ ge_summary_r\&cad $=0 \# \mathrm{v}=$ onepage\& $\mathrm{q} \& \mathrm{f}=$ false.

- COLOMBIA. Constitución Política de Colombia. (1991).

- COLOMBIA. Ley 65 de 1993. (19 de agosto). Por medio del cual se expide el código penitenciario y carcelario.

- COLOMBIA. Informe de la Contraloría delegada para el sector defensa, justicia y seguridad. Bogotá, junio de 2008.

- Denzin, Norman K. y Lincoln, Yvonna S. (1994). Manual experto de la investigación cualitativa. Tercera edición. Thousand Oaks: Sage Publications.

- Escobar, J. y Bonilla-Jimenez, F. I. (2011). Grupos focales: una guía conceptual y metodológica. Universidad El Bosque. En: Cuadernos Hispanoamericanos De Psicología, Vol. 9 No. 1, 51-67.

- INPEC. (2013). Informe de gestión. Consultado el 15 de noviembre de 2013. Recuperado en: http://www.inpec.gov.co/portal/page/portal/Inpec/Institucion/InformesDeGestion.

- INPEC. (2004). Plan de acción y sistema de oportunidades - PASO: Una estrategia para el tratamiento penitenciario.

- Foucault, M. (2002). Vigilar y castigar: nacimiento de la prisión. Buenos Aires: Edit. Siglo XXI.

- Max-Neef, M. A. (1993). Desarrollo a escala humana. Conceptos, aplicaciones y algunas reflexiones. Montevideo: Editorial Nordam-Comunidad.

- PNUD. (1990). Informe sobre desarrollo humano. Disponible en: http://hdr.undp.org/es/informes/mundial/idh1990/

- Sánchez Capdequí, C. (1999) Imaginación y sociedad: una hermenéutica creativa de la cultura, Tecnos-Universidad Pública de Navarra, Madrid.

- Taylor, S.J. y Bodgan, R. (1994). Introducción a los métodos cualitativos de investigación. Madrid: Dykinson. $2^{a}$ reimpresión, pp. 100-132.

- UNIVERSIDAD NACIONAL DE COLOMBIA, INPEC. (2008). Caracterización de escenarios $y$ gestiones de los consejos de evaluación y tratamiento (CET). Recuperado en: http://extension. upbbga.edu.co/web2/pagina2/archivos/DIAGNOSTICO.pdf. 